\title{
Study of Bacteriological pathogen causing neonatal sepsis at NICU in Ad-din medical college hospital
}

\author{
M Begum 1', M Hassan² , Z S M Haque ${ }^{3}$, N Jahan ${ }^{4}$, K Chowdhury ${ }^{5}$, A W S Rob ${ }^{6}$
}

1 Dr. Marium Begum Asst. Prof. of Neonatology Ad-din Medical College Hospital Dhaka

2

2 Dr. Mahmuda Hassan Associate Professor

3

Haque

Professor

4

Asst. Professor

5

${ }^{5}$ Dr. Kona chowdhury Asst. Professor

6 Dr. A W S Rob

Asst. Professor

$2,3,4,5,6$

Dept. of Neonatology

Ad-din Medical College Hospital Dhaka

\section{Correspondence}

Dr. Marium Begum

Asst. Prof. of Neonatology

Ad-din Medical College Hospital

Dhaka

E. mail: mariumb71@yahoo.com
Abstract

Objective : To determine the common causative bacterial agents of neonatal sepsis and their antimicrobial susceptibility in NICU

Methods : Newborns with clinical signs of septicemia and positive blood culture during twelve months were prospectively studied Samples for blood cultures, complete blood count, C-reactive protein, sugar, electrolytes were obtained; ampicillin and gentamycin were started empirically.

Result : Seven hundred and three neonates were investigated to rule out of sepsis. The male, female ratio was $1.3: 1$ and $56(63.63 \%)$ of patients were preterm and $32(36.36 \%)$ were term neonates. There were $68(77.27 \%)$ cases of Early onset neonatal sepsis (EONS) and $20(22.64 \%$ ) of Late onset neonatal sepsis (LONS). Coagulase negative staphylococcus (CONS) was the most common $37(42.04 \%) \mathrm{Gm}+\mathrm{ve}$ pathogen causing early onset neonatal sepsis and Acinetobacter was common Gm-ve pathogen in both early onset $16(18 \%)$ and late-onset 8 $(9 \%)$ sepsis. CONS sepsis showed high degree of resistance to commonly used antibiotics; ampicillin $(86.5 \%)$, oxacillin $(60 \%)$,cefotaxime $(67 \%)$ but comparatively low resistance to vancomycin $(0 \%)$, gentamicin $(25 \%)$, Levofloxacin $(36 \%)$ \& Imipenem $(49 \%)$. Acinetobacter were highly resistant to ampicillin (100), gentamicin(75\%), cefotaxime(100) and sensitive to Amikacin $(58.33 \%)$, ciprofloxacin $(54.16 \%)$, Levofloxacin and Imipenem (62.5\%)and Colistin (95.83\%).

Conclusion : Neonatal sepsis in our NICU is mainly caused by gram positive organisms, which are developing resistance to commonly used antibiotics. The initial empirical choice of Ampicillin and Gentamicin appears to be unreasonable for our environment.

Key Words : Septicemia; EONS- Early onset neonatal sepsis, LONS. Late onset neonatal sepsis, CONS. Coagulase negative staphylococcus, Antibiotic sensitivity.

\section{Introduction}

Sepsis neonatorum is the term used to describe any systemic bacterial infection documented by a positive blood culture in the first month of life ${ }^{1}$. Sepsis appearing from birth to seven days is called Early onset neonatal sepsis (EONS) and late onset neonatal sepsis (LONS) were defined as illnesses appearing from eight to twenty-eight days postnatal period. Neonatal septicemia remains one of the important causes of mortality and morbidity despite considerable progress in hygiene, introduction of new and potent antimicrobial agents and advanced measures for diagnosis and treatment ${ }^{2}$. Up to $10 \%$ of infants have infections in the first month of life $^{3}$ which are responsible for $30-50 \%$ of total neonatal deaths in developing countries ${ }^{4}$. The World Health Organization estimated that there are approximately four million neonatal deaths occur worldwide every year, $98 \%$ of which occur in developing countries, particularly Asia and Africa ${ }^{5,6}$. A number of organism is associated with neonatal sepsis and bacterial pathogens may vary from one country to another and within a country from one hospital or region to another ${ }^{7}$. These organisms may even vary at different times within the same place ${ }^{8,9}$. In developed countries Group B streptococcus (GBS), E.coli and Listeria monocytogenes are the most common causes of neonatal sepsis, however, in developing countries, these bacteria are replaced by gram-negative bacilli, Coagulase negative staphylococcus (CONS) and others ${ }^{10}$. Over the last two decades most of the organisms have developed increased drug resistance and management of the patients is becoming a major problem $^{11}$. Identification of the etiology is important since it can induce a change in management policy ${ }^{7}$. For effective management of neonatal septicemia with appropriate antibiotics that would minimize the risk of severe morbidity and mortality \& to reduce the emergence of multi-drug resistant organisms by rational antibiotic use, study of bacteriological profile and their antibiotic sensitivity pattern plays a significant role ${ }^{1,12}$. The present study was carried out to determine the bacteriological profile with antibiotic sensitivity pattern of neonatal sepsis in NICU Ad-din Medical college \& hospital.

\section{Subjects \& Methods}

In a cross sectional descriptive study, a total of 703 neonates ( 0 to 28 days of age) were investigated who were admitted to rule out sepsis in NICU at Ad-din Medical College Hospital over a period of 13 months (January 2012 to January 2013). Both premature and full terms, inborn and out born were included in the study. Written informed consent was obtained from their parents/guardians and was investigated for bacterial etiologic agents. Demographic, clinical and other relevant data were obtained by questionnaire 
prepared for this study. Early onset neonatal sepsis (EONS) and late onset neonatal sepsis (LONS) were defined as illnesses appearing from birth to seven days and from eight to twenty-eight days postnatal respectively Blood culture, chest X-ray and laboratory tests including complete blood count (CBC), C-reactive protein (CRP),blood sugar (BS) and electrolytes were performed for all subjects.

Using aseptic technique by applying Povidone iodine and $70 \%$ alcohol at the site of vein puncture, $2 \mathrm{ml}$ venous blood was drawn from the peripheral vein by the attending nurse and then the blood was inoculated into a blood culture bottle containing Tryptone Soy Broth (TSB) and Brain Heart infusion Broth. The specimens were transported immediately to microbiological laboratory and incubated for one week in $37^{\circ} \mathrm{C}$ and were daily checked for evidence of bacterial growth. For positive broth cultures, subcultures were made on solid media (blood agar and McConkey agar) and were incubated in $37^{\circ} \mathrm{C}$ for 24 to 48 hours. The grown bacteria were identified by colony morphology, gram stain and biochemical tests. Antimicrobial susceptibility testing was performed for all blood culture isolates according to the criteria of the National Committee for Clinical Laboratory Standards by disk diffusion method

Results : Positive blood cultures were obtained for 88 neonates (13\%). Among them 45 (51.12\%) with gram positive bacteria and 43 (48.84\%) had sepsis with gram negative bacteria. The most common gram positive bacteria was Coagulase Negative Staphylococci (CONS) 37 $(42.07 \%)$, other were Staphyolo coccus $5(5.68 \%)$, Enterococcus 3 (3.40\%) and gram negative bacteria were Acinetobacter 24 (27.27\%), Pseudomonas spp. $8(9.09 \%)$, Klebsiella Pneumoniae $5(5.68 \%)$, Moraxella 3 (3.40\%) and Enterobacter 3 (3.40\%) (Table 1).

Table I: Types of micro organism in early and late onset neonatal sepsis

\begin{tabular}{|l|l|l|l|l|l|}
\hline Sepsis organism & \multicolumn{2}{|c|}{ Early onset } & \multicolumn{2}{c|}{ Late onset } & Total \\
\hline & Preterm & Term & Preterm & Term & \\
\hline CONS & $18(20.04 \%)$ & $15(17.04 \%)$ & $3(3.40 \%)$ & $1(1.13 \%)$ & $37(42.04 \%)$ \\
\hline Staphyolo coccus & $2(2.27 \%)$ & $3(3.40 \%)$ & 0 & 0 & $5(5.68 \%)$ \\
\hline Entero coccus & $2(2.27 \%)$ & $1(1.13 \%)$ & 0 & 0 & $3(3.40 \%)$ \\
\hline Acinetobacter & $11(12.50 \%)$ & $5(5.68 \%)$ & $6(6.81 \%)$ & $2(2.27 \%)$ & $24(27.27 \%)$ \\
\hline Pseudomonas & $5(5.68 \%)$ & $2(2.27 \%)$ & $1(1.13 \%)$ & 0 & $8(9.09 \%)$ \\
\hline Klebsiella & 0 & $1(1.13 \%)$ & $2(2.27 \%)$ & $2(2.27 \%)$ & $5(5.68 \%)$ \\
\hline Enterobacter & $1(1.13 \%)$ & 0 & $2(2.27 \%)$ & 0 & $3(3.40 \%)$ \\
\hline Morexiella & $2(2.27 \%)$ & 0 & $1(1.13 \%)$ & 0 & $3(3.40 \%)$ \\
\hline Total & $41(46.59 \%)$ & $27(30.68 \%)$ & $15(17.04 \%)$ & $5(5.602 \%)$ & $88(100 \%)$ \\
\hline
\end{tabular}

68 patients (77.27\%) had early onset and 20 (22.64\%) had late-onset neonatal sepsis. Coagulase Negative Staphylococci (CONS) was the most isolated prevalent gram positive bacteria 37 (42.04\%) and common in early onset neonatal sepsis $(48.52 \%)$. Acinetobacter was common pathogen in both early onset $16(65 \%)$ and late-onset 8 (35 $\%)$ sepsis. Among 88 newborns with sepsis, 56 (63.63\%) were preterm and $32(36.28 \%)$ were term.
Table II: Distribution of neonates according to neonatal characteristics $(n=88)$ :

\begin{tabular}{|l|l|l|l|l|l|}
\hline Neonatal characteristics & & Total No(\%) & Early onset & Late onset & Expired \\
\hline Sex & Male & $51(57.95 \%)$ & $39(44.31 \%)$ & $12(13.63 \%)$ & $3(3.40 \%)$ \\
\cline { 2 - 6 } & Female & $37(42.04 \%)$ & $26(29.54 \%)$ & $10(11.36 \%)$ & $2(2.27 \%)$ \\
\hline \multirow{3}{*}{ Place of delivery } & In born & $63(71.59 \%)$ & $46(52.27 \%)$ & $17(19.31 \%)$ & $2(2.27 \%)$ \\
\cline { 2 - 6 } & Out born & $25(28.40 \%)$ & $19(21.59 \%)$ & $6(6.81 \%)$ & $3(3.40 \%)$ \\
\hline \multirow{3}{*}{ Birth weight } & LUCS & $56(63.63 \%)$ & $40(45.45 \%)$ & $16(18.18 \%)$ & $4(4.54 \%)$ \\
\cline { 2 - 6 } & NVD & $32(36.36 \%)$ & $25(28.40 \%)$ & $7(7.95 \%)$ & $1(1.13 \%)$ \\
\hline & $>2500 \mathrm{gm}$ & $27(30.68 \%)$ & $24(27.27 \%)$ & $3(3.40 \%)$ & $1(1.13 \%)$ \\
\cline { 2 - 6 } & $<2500 \mathrm{gm}$ & $61(69.31 \%)$ & $41(46.59 \%)$ & $20(22.72 \%)$ & $4(4.54 \%)$ \\
\hline
\end{tabular}

There were $61(69.31 \%)$ neonates with low birth weight and 27 newborns $(30.68 \%)$ with normal birth weight. Considering sex preponderance there were more cases of sepsis in male neonates in comparison to female (51 male and 37 female with 1.3:1 ratio). The mortality rate was $5(5.68 \%)$ in this study (Table 2$)$. Death were comparatively higher in out born $(3.40 \%)$ then in born $(2.27 \%)$ neonates. Most of the neonates were delivered by LUCS and motility was also higher in this group (4.5\%).

Table III : Sensitivity pattern of common micro-organism

\begin{tabular}{|l|l|l|l|l|l|l|}
\hline Drug & $\begin{array}{l}\text { CoNS } \\
(\mathbf{n = 3 7})\end{array}$ & $\begin{array}{l}\text { Staphyl c. } \\
\text { aureous } \\
(\mathbf{n = 5})\end{array}$ & $\begin{array}{l}\text { Acinetobacter } \\
(\mathbf{n = 2 4})\end{array}$ & $\begin{array}{l}\text { Pseudomonus } \\
(\mathbf{n = 8})\end{array}$ & $\begin{array}{l}\text { Klebsiella } \\
(\mathbf{n = 5})\end{array}$ & $\begin{array}{l}\text { Enterobacter } \\
(\mathbf{n = 3})\end{array}$ \\
\hline Ampicillin & $5(13.5 \%)$ & 0 & 0 & 0 & 0 & 0 \\
\hline Gentamicin & $28(75.67 \%)$ & $5(100 \%)$ & $6(25 \%)$ & $3(37.50 \%)$ & 0 & 0 \\
\hline Amikacin & NT & NT & $14(58.33 \%)$ & $6(75.0 \%)$ & $3(60 \%)$ & 0 \\
\hline Oxacillin & $15(40.54 \%)$ & $2(40 \%)$ & NT & NT & NT & NT \\
\hline Vancomycin & $37(100 \%)$ & $5(100 \%)$ & NT & NT & NT & NT \\
\hline Ciprofloxacin & $16(43.24 \%)$ & $2(40 \%)$ & $13(54.16 \%)$ & $4(50 \%)$ & $2(40 \%)$ & $3(100 \%)$ \\
\hline Levofloxacin & $24(64.86 \%)$ & $3(60 \%)$ & $15(62.5 \%)$ & $5(62.5 \%)$ & $3(60 \%)$ & $3(100 \%)$ \\
\hline Imepenem & $19(51.35 \%)$ & $5(100 \%)$ & $15(62.5 \%)$ & $6(75 \%)$ & $4(80 \%)$ & $3(100 \%)$ \\
\hline Cefotaxime- & $5(13.5 \%)$ & $2(40 \%)$ & 0 & 0 & 0 & 0 \\
\hline Colistin & NT & NT & $23(95.83 \%)$ & $8(100)$ & $5(100 \%)$ & $3(100 \%)$ \\
\hline Piperacillin & NT & NT & $10(41.66 \%)$ & $6(75.0 \%)$ & $3(60 \%)$ & $3(100 \%)$ \\
\hline
\end{tabular}

Based on the results from susceptibility testing, all of the isolated gram positive bacteria poorly sensitive to Ampicillin(13.5\%) and Cefotaxime (13.5\%) and highly sensitive to Vancomycin (100\%) and Gentamicin (75.67\%). All of the gram negative isolates were resistant to Ampicillin and Cefotaxim. Acinatobacter had low sensitivities to Gentamicin (25\%). Sensitivity to Amikacin (58.33\%), Imepenem and Levofloxacin (62.5\%), and Colistin (95.65\%). Pseudomonas had sensitivity $75 \%$ to Amikacin, Imepenem and Piperacillin. Colistin had highly sensitive to Pseudomonus, Klebsiella pneumonae, Enterobacter.

\section{Discussion}

Neonatal Sepsis is the commonest cause of neonatal morbidity and mortality. Low birth weight is an important risk factor contributing to sepsis. Among 88 babies who developed neonatal sepsis during the study period $69.31 \%$ (61 cases) neonates with low birth weight, this is 
similar with other studies where LBW was found to be important risk factor for sepsis. ${ }^{13,14}$ LBW babies are mostly premature are predispose to sepsis due to multiple reasons like immune incompetence at various level of defense, and needed to invasive intervention etc. Considering sex preponderance there were more cases of sepsis in male neonates in comparison to female (51 male and 37 female with 1.3:1 ratio). Other study also shows male female ratio nearly $2: 1^{2}$, this could be gender biasness in presentation to the hospital for care. Population based studies would be needed to address this important question.

In this study documented neonatal sepsis with positive culture was $13 \%$. This is low compared to about $20 \%$ yield reported by Baltimore ${ }^{15}$ and Gladstone ${ }^{16}$. Earlier, culture positive rate of $26 \%$ by Ahmed ${ }^{2}$ and much higher rates of $51 \%$ by Karthikeyan ${ }^{17}$ and $64 \%$ by Tallur ${ }^{18}$ was described. In the present investigation, $77.27 \%$ and $22.64 \%$ neonates presented with EONS and LONS respectively. We found that early onset sepsis (EONS) was more common than late onset sepsis (LONS), which is in agreement with the reports from other developing countries e.g. in Iran $^{11}(77.5 \%$ vs. $22.5 \%)$ and in a study of Bangladesh ${ }^{19}$ (70.7 vs. $29.3 \%$ ), but in contrast with reports from Saudi Arabia (39\% vs. $61 \%)^{20}$ and Pakistan (42\% vs.58\%) ${ }^{21}$, where late onset sepsis is more common. The possible explanation for a higher frequency of EONS in this study might be the more referral of preterm labors and preterm newborns to our center. Isolation of gram positive and gram negative bacteria in this study were $51.13 \%$ and $48.86 \%$, respectively. This finding is similar to that of other studies where gram positive bacteria were the commonest cause of neonatal sepsis ${ }^{22,23}$ This was in contrast to other studies which showed that gram negative bacteria were responsible in most cases of neonatal sepsis ${ }^{11,21}$. In the present study in case of EONS, gram positive and gram negative bacteria accounted for $60.29 \%$ and $39.71 \%$ respectively.

Gram-positive organisms constituted the major group of isolates $(51.13 \%)$ from neonatal septicemia cases. In general, Coagulase Negative Staphylococci was the most common isolates $(42.04 \%)$ causing neonatal sepsis in this study and it was the commonest cause of early onset neonatal sepsis (48.52\%) and the rest included staphylococcus aureus (5.68\%) and Enterococcus (3.40\%). The predominance of gram positives correlated the findings of other workers. ${ }^{24,25}$ Other authors ${ }^{9,24}$ have reported increasing trend of CONS in neonatal sepsis. Studies from different countries report CONS as the predominant organisms in LONS $^{26}$. In other studies gram positive bacteria such as $\mathrm{S}$. aureus and group B streptococcus (GBS) were found to be the most common isolates in neonatal septicemia22. Proinflammatory responses to $\mathrm{S}$. epidermidis are dependent on gestational age in preterm infants ${ }^{27}$, thus the predominance of neonatal sepsis in preterm newborns in our study may be one reason to this finding. The variance of bacteriologic growth is not clear but it may be the population difference with regard to the maternal colonization rate, nosocomial acquisition of bacteria by the mother and the neonate, genetics of the immune response in selected population groups ${ }^{8}$.

Acinetobacter (18\%) and Pseudomonas(7.95\%) spp. were the most common gram negative organisms in early onset neonatal sepsis. In late onset sepsis, Acinetobacter (9.08\%) was the predominant organism. In general, Acinetobacter was the $2^{\text {nd }}$ most common isolates $(27.27 \%)$ causing neonatal sepsis in this study. Pseudomonas was the $3^{\text {rd }}$ most common organism isolated in this study. The pattern of isolated organisms in our study slightly differs from the findings in Iran ${ }^{11}$ where Pseudomonas Aeruginosa was the most common cause of neonatal sepsis followed by Klebsiella spp. and E. coli. In a similar study from Bangladesh, Nepal and Pakistan, E. coli was the leading cause of neonatal sepsis followed by Klebsiella $\mathrm{spp}^{2,21}$.

Coagulase negative staphylococcus (CONS), S. Aureus and other gram positive organisms in our study were better susceptible to Gentamicin (75.67\%), Vancomycin (100\%), Imipenem (51.35\%). Described in the literature Staphylococcus was resistant to Ampicillin ${ }^{28}$ in $79.3 \%$ of the cases and low sensitivity to all commonly used antibiotics ${ }^{17}$. Acinetobacter was best susceptible to Imipenem (62.5\%), Amikacin $(58.33 \%)$, Ciprofloxacin $(54.18 \%)$, Levofloxacin $(62.5 \%)$, Colistin $(95.83 \%)$ and less susceptible to Gentamicin (25\%) and completely resistant to Ampicillin ${ }^{17}$, Cefotaxime. Higher susceptibility to Amikacin was reported by Ramesh ${ }^{29(34)}$. Pseudomonas species were susceptible to Amikacin (75\%), Gentamicin (37.50\%), Imepenem (75\%), Levofloxacin (62.5\%), Piperacillin (75.\%), Colistin (100\%) and completely resistant to Ampicillin and cefotaxime. Low sensitivity to ampicillin is similar to many earlier study. ${ }^{23,18}$ Lower susceptibility to Amikacin (45\%) was found by Agarwal. ${ }^{30}$

The antimicrobial sensitivity pattern differs in different studies as well as at different times in the same hospital ${ }^{31}$. This may be due to emergence of resistant strains as a result of indiscriminate use of antibiotics. The high resistance rates found in this study may be associated with the frequent use of antimicrobial drugs for both prophylactic and therapeutic treatment of hospitalized newborns $\mathrm{s}^{32}$. In view of the above facts the strategy of antibiotic usage in neonates should be reviewed periodically even in the same hospital

\section{Conclusion}

CONS and Acinetobacter together with Pseudomonas are the leading causative agents of neonatal sepsis in our unit. They were resistant to commonly used antibiotics, thus due to antibiotic sensitivity results, appropriate initial empirical antibiotic therapy for neonatal sepsis should be replaced. Every unit should carefully follow the bacterial spectrum and resistance patterns of microorganism responsible for neonatal infections to design a specific empirical antibiotic regimen for unit.

\section{Acknowledgment}

We gratefully acknowledge Ad-din Medical College and Hospital and department of NICU.

\section{References}

1. Edwards MS. Postnatal infections. In:Neonatal-Perinatal Medicine. Edited by Fanaroff, Martins, 8th ed. Philadelphia, Mosby Elsevier 2006;Pp: 791-804.

2. Ahmed AS, Chowdhury MA, Hoque M, Darmstadt GL. Clinical and bacteriological profile of neonatal septicemia in a tertiary level pediatric hospital in Bangladesh. Indian Pediatr. 2002;39(11):1034-9.

3. Zupan J, Aahman E, Perinatal mortality for the year 2000: estimates developed by WHO. Geneva: World Health Organization.2005.

4. Stoll BJ. The global impact of neonatal infection. Clin Perinatol1997;24:1-21.

5. Stoll BJ. Infections of the neonatal infant. In: Kliegman RM, Behrman RE, Jenson HB (eds). Nelson Textbook of Pediatrics. $18^{\text {th }}$ ed. Philadelphia;Saunders. 2007, Pp: 794- 811. 
6. Jain NK, Jain VM, Maheshwari S. Clinical profile of neonatal sepsis. Katmandu Uni Med J (KUMJ) 2003;1(2):117-20.

7. Desinor OY, Silva JL, Menos MJ. Neonatal sepsis and meningitis in Haiti. J Trop Pediatr. 2004;50(1):48-50.

8. Aurangzeb B, Hameed A. Neonatal sepsis in hospital-born babies: bacterial isolates and antibiotic susceptibility patterns. J Coll Physicians Surg Pak. 2003, 13(11):629-32.

9. Hufnagel M, Burger A, Bartelt $S$, et al. Secular trends in pediatric bloodstream infections over a 20-year period at a tertiary care hospital in Germany. Eur J Pediatr. 2008.

10. Palazzi D, Klein J, Baker C. Bacterial sepsis and meningitis. In: Remington JS, Klein J (eds). Infectious Disease of the Fetus and Newborn Infants. 6th ed. Philadelphia; Elsevier Saunders. 2006;Pp: 247-95.

11. Movahedian A, Moniri R, Mosayebi Z. Bacterial culture of neonatal sepsis.Iranian J Publ Health. 2006; 35(4):84-910. Chacko B, Sohi I. Early onset neonatalsepsis. Indian J Pediatr. 2005;72(1):23-6.

12. Chacko B, Sohi I. Early onset neonatal sepsis. Indian J Pediatr. 2005;72(1):23-6.

13. Khinchi YR, Shreshta D, Sarmah BK et al. A study of morbidity and mortility profile of neonates admitted intertiary care hospital in central Nepal. Journal of college of medical science. Nepal,2008; 75: 70-5.

14. Jeeva Sanker M, Agrawal R, Deorari AK et al. Sepsis in neoborn. Indian J Pediatr 2008; 75: 261-66.

15. Baltimore RS, Huie SM, Meek JI, Schuchat A, O'Brein KL: Early-onset neonatal sepsis in the era of group B Streptococcal prevention. Pediatrics 2001;108:1094-98

16. Gladstone IM, Ehrenkranz RA, Edberg SC, Baltimore RS: A ten-year review of neonata sepsis and comparison with the previous fifty-year experience. Pediatr Infect Dis J 1990;9:819-25.

17. Karthikeyan G, Premkumar K: Neonatal sepsis: Staphylococcus aureus as the predominant pathogen. Indian J Pediatr 2001;68:715-17.

18. Tallur SS, Kasturi AV, Nadgir SD, Krishna BVS: Clinico-bacteriological study of neonatal septicemia in Hubli. Indian J Pediatr 2000; 67:169-74.

19. Rasul $\mathrm{CH}$, Hassan MA, Habibullah M. Neonatal sepsis and use of antibiotic in tertiary care hospital. Pak J Med Sci. 2007;23:78-81

20. Umran K, Twum-Danso K. A case control study of neonatal sepsis: Experience from Saudi Arabia.J Trop Pediatr. 1997;43:84-8.
21. Aftab R, Iqbal I. Bacteriological agents of neonatal sepsis in NICU at Nishtar Hospital Multan. J Coll Physicians Surg Pak. 2006;16:216-9

22. Robillard PY, Nabeth P, Hulsey TC, Sergent MP, Périanin J, Janky E. Neonatal bacterial septicaemia in a tropical area. Four-year experiences in Guadeloupe (French West Indies).Acta Paediatr 1993; 82:687 -9.

23. Hyde TB, Hilger TM, Reingold A, Farley MM, O'Brien KL, Schuchat A; Active Bacterial Core surveillance $(A B C S)$ of the Emerging Infections Program Network. Trends in incidence and antimicrobial resistance of early-onset sepsis: population-based surveillance in San Francisco and Atlanta.Pediatrics 2002;110:690 -5.

24. Ghadamli P. Neonatal sepsis in Shaheed Beheshti teaching hospital (Persian). J Qazvin Uni Med Sci. 1998;7(6):53-7.

25. Gheibi Sh, Haghi S, Soleimani Sh. Mortality and septicemia in neonates admitted into the NICU of Imam Khomeini Hospital of Urmia (Persian).Med J Tabriz Uni Med Sci. 2005;27(3):69-73.

26. Munson DP, Thompson TR, Johnson DE, Rhame FS, VanDrunen N, Ferrieri P. Coagulasenegative staphylococcal septicemia: experience in a newborn intensive care unit. ] Pediatr. 1982;101:602-5.

27. Hartel C, Osthues I, Rupp J, et al. Characterization of the host inflammatory response to Staphylococcus epidermidis in neonatal whole blood. Arch Dis Childh. 2008.

28. Aurangzeb B, Hameed A: Neonatal sepsis in hospital -born babies: Bacterial isolates and antibiotic susceptibility patterns. J Coll Physicians Surg Pak 2003;13:629-32.

29. Ramesh Bhat Y, Leslie ES Lewis, Vandana KE. Bacterial isolates of early-onset neonatal sepsis and their antibiotic susceptibility pattern between 1998 and 2004: an audit from a center in India. Indian Journal of Pediatrics 2011; 37:32

30. Agrawal M, Chaturvedi P, Dev SK, Narang P: Coagulase negative staphylococcal septicemia in new borns. Indian pediatr 1990; 27:163-69.

31. Mathur M, Shsh $\mathrm{H}$, Khambadkone $\mathrm{S}$, et al.Bacteriological profile of neonatalsepticemia cases (for the year 1990-91). J Postgrad Med. 1994;40(1):18-20.

32. Loureiro MM, Moraes BA, Quadra MRR, et al. Study of multi-drug resistant microorganisms isolated from blood cultures of hospitalized newborns in Rio de Janeiro city, Brazil. Brazil J Microbiol. 2002;33(1):73-8. 